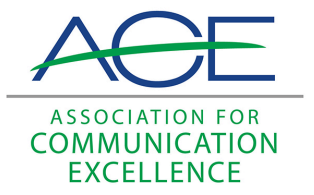

Journal of Applied Communications

\title{
Perceptions Of A Master Of Science Degree In Agricultural Communication By Agricultural communicators In Education (ACE): A National Study
}

Colleen Wilson

Curtis E. Paulson

Janet L. Henderson

Follow this and additional works at: https://newprairiepress.org/jac c) (1) (2)

This work is licensed under a Creative Commons Attribution-Noncommercial-Share Alike 4.0 License.

\section{Recommended Citation}

Wilson, Colleen; Paulson, Curtis E.; and Henderson, Janet L. (1991) "Perceptions Of A Master Of Science Degree In Agricultural Communication By Agricultural communicators In Education (ACE): A National Study," Journal of Applied Communications: Vol. 75: Iss. 2. https://doi.org/10.4148/1051-0834.1499

This Research is brought to you for free and open access by New Prairie Press. It has been accepted for inclusion in Journal of Applied Communications by an authorized administrator of New Prairie Press. For more information, please contact cads@k-state.edu. 


\title{
Perceptions Of A Master Of Science Degree In Agricultural Communication By Agricultural communicators In Education (ACE): A National Study
}

\author{
Abstract \\ A sample of 254 ACE members was surveyed to determine the components of a Master of Science \\ degree in Agricultural Communication.
}




\title{
Perceptions Of A Master Of Science Degree In Agricultural Communication By Agricultural Communicators In Education (ACE): A National Study
}

\author{
Colleen Wilson \\ Curtis E. Paulson \\ Janet L. Henderson
}

A sample of $254 \mathrm{ACE}$ members was surveyed to determine the components of a Master of Science degree in Agricultural Communication. The highest ranked components included: writing, communication technology, understanding and evaluating research, and mass communication theory. The majority of ACE members indicated that a Master of Science degree was needed, that the degree should provide a broad spectrum of communication and agricultural subject areas, that introductory communication and agricultural courses should be taken as conditional requirements, that the primary focus of the degree should be communication skill development, and that the program should be housed in Agricultural Communication.

\section{INTRODUCTION}

Little information is available concerning graduate level degree programs in agricultural communication. Undergraduate degree programs exist in numerous colleges and universities across the nation; however, only one university currently offers a master's degree in Agricultural Communication. Several other schools offer graduate programs that combine agriculture and communication interests, but the majority of available courses are

Colleen Wilson is a graduate of the master's program in Agricultural Education at The Ohio State University. Curtis E. Paulson is an assistant professor, Agricultural Communication at The Ohio State University. Janet L. Henderson is an associate professor, Agricultural Education at The Ohio State University. The article was presented as a paper at the 1991 International Meeting of the Agricultural Communicators in Education (ACE) Annual Meeting, Rapid City, South Dakota, June 29 July $2,1991$.

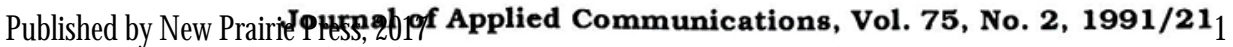




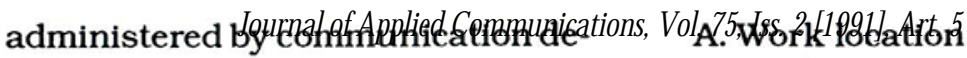

partments.

This study gathered information on graduate level degree programs and curriculum development in agricultural communication, and specifically a Master of Science degree in Agricultural Communication. This study focused on the perception of members belonging to one national, professional communication organization, Agricultural Communicators in Education (ACE). Members of ACE were surveyed to determine their perceptions of the necessity and curriculum content areas of a graduate level degree in Agricultural Communication.

\section{Purpose and Objectives}

The nature of this study was descriptive-correlational research. The purpose of this study was to determine the perceptions of a Master of Science degree in Agricultural Communication by the members of Agricultural Communicators in Education. The following objectives were established.

1. To describe ACE members on the following demographic characteristics:

A. Number of years worked in the field of communication

B. Number of years worked in the field of agricultural communication

C. Number of years as an ACE member

D. Membership in other professional communication organizations

E. Highest academic degree

F. Major(s) in college

G. Age

H. Gender

2. To describe current employment information of ACE members on the following items:
B. Work position

C. Job responsibilities

D. Job title

E. Personnel composition of the work place

F. Number of people supervised

G. Percent of time spent on administrative duties

H. Percent of time spent on production activities

I. Percent of time spent on formal classroom teaching

J. Percent of time spent on research activities

3. To determine the perceptions of ACE members of the necessity of a Master of Science degree in Agricultural Communication.

4. To determine the perceptions of ACE members of what content areas should be included in a Master of Science degree in Agricultural Communication.

5. To determine the perceptions of ACE members of what academic department should house a Master of Science degree in Agricultural Communication.

6. To determine the perceptions of ACE members of what should be the academic major for a graduate student interested in the field of agricultural communication.

7. To determine the relationships between perceptions of the necessity of a Master of Science degree in Agricultural Communication and selected member demographic characteristics and current employment information.

8. To determine the relationships between perceptions of what content areas should be included in a Master of Science degree in Agricultural Communication and selected member demographic characteristics and current employment information. 


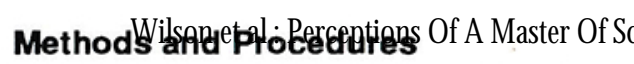

The target population for the study was members of ACE $(\mathrm{N}=677)$. A random sample of the 1991 ACE membership roster was chosen for the sample. The sample $(n=254)$ was randomly selected using computer generated numbers. The sample size of 254 respondents is 38 percent of the target population. The results of the study are generalized to the target population.

The survey instrument was a questionnaire designed by the researchers. The instrument was developed based on consultations with communication professionals, faculty members, and graduate student peers. Content validity was established by an eight-member panel of experts consisting of faculty and graduate students of the Department of Agricultural Education, The Ohio State University and the head of the Section of Information and Applied Communication, The Ohio State University. The instrument was pilot tested with $11 \mathrm{ACE}$ members at the Section of Information and Applied Communication, The Ohio State University. Test-retest procedures were used to determine coefficients of stability for section one of the instrument. The coefficients of stability ranged from 45 percent to 100 percent, with an average of 86 percent. The information collected from the validity and reliability tests was used to modify the questionnaire before distribution to the individuals in the sample.

The instrument was divided into three sections. Section one consisted of three parts. Part A listed 26 items designed to determine ACE members' perceptions of what content areas should be included in a Master of Science degree in Agricultural Communication. Responses to these items were scaled on a six

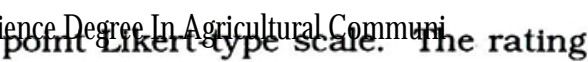
scale included: Firmly Disagree $=1$, Disagree $=2$, Slightly Disagree $=3$, Slightly Agree $=4$, Agree $=5$, and Firmly Agree $=6$.

Part $\mathrm{B}$ included five items. The stem phrase for each item was written in an either/or format. Members chose one of two options as their response. Each item pertained to procedures within a Master of Science degree in Agricultural Communication.

Part C included four items. Members were asked to rank, in order, their responses for the first three questions pertaining to departmental location of the degree, primary focus of the degree, and academic major for a graduate student interested in the field of agricultural communication. The fourth item measured ACE members' perceptions of the necessity of a Master of Science degree in Agricultural Communication. Members were asked to circle either "yes" or "no" and provide written comments supporting their responses.

Section two of the instrument gathered data on current employment information, and section three collected data on selected demographic characteristics. One openended question was included on the back cover of the questionnaire. This question asked for additional comments regarding a Master of Science degree in Agricultural Communication.

The instrument design followed guidelines suggested by Dillman (1978). The questionnaire format was a 12-page, five and one half-inch by eight and one half-inch booklet.

Questionnaires were mailed on March 22, 1991 to the sample population. ACE members received a packet containing a cover letter, a questionnaire, and a self-addressed, 


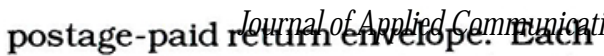
questionnaire contained an identification code number on the back cover for non-response follow-up. By April 8, 1991, 47 percent ( $n=119)$ of the questionnaires had been returned.

A second mailing, including a revised cover letter, a questionnaire, and a self-addressed, postage-paid return envelope, was sent to all nonrespondents on April 10, 1991. An additional 42 questionnaires were returned for a total data sample of $\mathrm{n}=161$ (63 percent). The final data sample included 157 useable questionnaires for a 62 percent response rate: four of the questionnaires were deleted from the data sample due to incomplete responses.

The researchers collected selected demographic characteristics on all of the non-respondents $(n=93)$. No significant differences were found between non-respondents and respondents for this study; therefore, sample population results were generalized to the target population.

Responses to the items on the questionnaire were coded and analyzed using the Statistical Package for Social Sciences (SPSS/PC+) program in the Department of Agricultural Education, The Ohio State University. Descriptive statistics were used to organize and summarize the data. Frequencies, percentages, measures of central tendency (mean, mode, median), and measures of variability (range, standard deviation) were computed. Correlational coefficients were calculated to describe the levels and directions of association between the variables at the .05 level of significance.

\section{Findings}

The first section of the questionnaire asked members' perceptions of

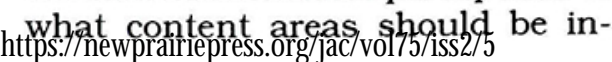

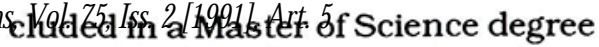
in Agricultural Communication. Twenty-six statements of opinion measured responses on a six point Likert-type scale. The five content areas with the highest mean scores included: writing (mean $=5.41$ ), communication technology (mean=5.19), understand and evaluate the research of others (mean=5.10), mass communication theory (mean=5.07), and information diffusion theories and research (mean=5.03). All content areas except two (psychology and personnel management) had mean scores of four or higher, indicating positive responses.

Five other content areas or procedures for a Master of Science degree in Agricultural Communication were analyzed. Sixty-six percent of ACE members indicated that the degree should provide a broad spectrum of communication subject areas. Thirty-four percent indicated the degree should specialize in one communication subject area. A majority of ACE members (88 percent) maintained that the degree should require a broad agricultural base to augment the communication emphasis, while 12 percent of members maintained the degree should require one area of agricultural specialization to augment the communication emphasis.

Communication-based internships should be required for students with no prior work experience in communication, according to 56 percent of ACE members. An internship for all students was supported by 44 percent of ACE members.

Students without a communication-oriented bachelor's degree or work experience in communication should take introductory communication skill courses as conditional 
Wilson et al.: Perceptions Of A M aster Of Science Degree In A gricultural Communi

requirements, according to 68 percent of ACE members. Thirty-two percent of members indicated that introductory communication skill courses should be part of the Master of Science degree program. Fiftythree percent of ACE members agreed that students without agriculturallyoriented bachelor's degree or work experience in agriculture should take introductory technical agriculture courses as conditional requirements, while 47 percent of members agreed that introductory technical agriculture courses should be part of the Master of Science degree program. A majority of ACE members (62 percent) indicated that a Master of Science degree in Agricultural Communication is needed, and 35 percent of members indicated the degree is not needed. A majority of members (77 percent) also indicated that the primary focus of the master's degree should be communication skill development, rather than research or management skill development.

Members were asked to rank, in order, their choices for what department should house a Master of Science degree in Agricultural Communication. The department of Agricultural Communication was indicated as first choice by 67 percent of ACE members. Fifty-five percent of members also selected Agricultural Communication as the best major for a graduate student interested in the field of agricultural communication.

ACE members were asked to describe current employment information in the second section of the questionnaire. The majority of members (68 percent) listed landgrant universities as their work location. Fifty-eight percent of ACE members described their work position as administrative/ professional, and indicated the majority of their job responsibilities were production activities (54 percent). The personnel composition of members' work places was faculty and administrative/professional, and the average number of people supervised was 6 . However, the largest percentage of ACE members (38 percent) indicated that they do not supervise anyone.

Members were asked to summarize the amount of time they spend on administration, production, formal classroom teaching, and research activities. Eighty-one percent of ACE members responded that they spend less than 50 percent of time on administrative duties ( 0 percent time $=19$ percent), while 99 percent of members spend less than 50 percent of time on formal classroom teaching $(0$ percent time $=74$ percent $)$ and research activities $(0$ percent time $=63$ percent). Percent of time spent on production activities was more evenly split between percentages. Only 12 percent of members indicated they spend no time on production activities. The highest number of members (28 percent) spend between 76 percent and 99 percent of their time on production activities.

Selected demographic characteristics of the respondents in the third section of the questionnaire indicate that $\mathrm{ACE}$ members varied widely on number of years worked in the field of communication, number of years worked in the field of agricultural communication, number of years as an ACE members, and age. The average age of ACE members was 50 years. The average number of years worked in the field of communication was 22 years, with a range from 1 to 60 years. The average number of years worked in the field of agricultural communication was 17 years, with a range from 0 to 60 years. ACE members indicated they 
have belonged to the ACE organization for an average of 14 years. Membership years range from 1 to 47. The majority of ACE members (62 percent) indicated they earned a master's degree. All members earned degrees beyond the high school level. The gender of the population included 36 percent females and 64 percent males.

\section{Conclusions}

Based on the findings of the study, the researchers concluded that a Master of Science degree in Agricultural Communication is needed. There is currently only one university that offers specific graduate level degrees in Agricultural Communication, so the need for further curriculum development in this area exists.

Comments from respondents indicated that a master's degree is the key to advancement in the field of communication. Several respondents agreed that the degree will help people interested in management level positions, and make students aware of the latest policies, technology, and research in the communication field. Several other respondents indicated that highly trained individuals are needed to cope with the issues agriculture is currently facing. Others responded that the degree is needed to enhance credibility, and produce clear, concise, and targeted information. One ACE member currently enrolled in a university said, "It would be nice to specialize in my chosen field. I'm given much freedom in choosing courses in my program of study at this university, but it would be nice to have a master's in Agricultural Communication."

The factors indicated above suggest that a Master of Science degree in Agricultural Communication should be developed to meet the need for graduate level education. Perhaps the master's program can be developed and pilot tested at several colleges and universities for further study and refinement. Employers of graduates, educators, and school administrators can be useful resources in defining specific portions of the master's program.

ACE members indicated through the survey that an Agricultural Communication department should house the Master of Science degree in Agricultural Communication. Since only one such department exists nationwide, this research suggests that new departments should be developed to coordinate the graduate level program. Perhaps the Agricultural Communication department can act as the home base for the degree program and cooperate with other departments for course requirements already offered to avoid duplication of course content.

While the discussion so far has been about the need for and development of graduate level programs in agricultural communication, misgivings about the need for this type of program exist, and the issue is currently being debated by communication professionals. A portion of the survey respondents indicated that a Master of Science degree in Agricultural Communication is not needed. Many ACE members indicated that a master's degree is not necessary to communicate well and be productive in the communication profession. One member maintained that the majority of available jobs in this field are entry-level and only require bachelor's degrees, while another member indicated that a student with a bachelor's degree in 
Wilson et al.: Perceptions Of A M aster Of Science Degree In Agricultural Communi

Agricultural Communication and a master's degree emphasizing research should be adequate. Many members responded that a Master of Science degree in Agricultural Communication is too limited or narrow, and students should obtain a broader, more varied education.

While both "yes" and "no" responses were given as answers to the question concerning the necessity of a Master of Science degree in Agricultural Communication, the majority of ACE members indicated that the degree is needed.

\section{Content Areas of the Degree}

ACE members rated each content area to be included in a Master of Science degree in Agricultural Communication listed in the questionnaire as positive. The top five content areas included: writing, communication technology, understand and evaluate the research of others, mass communication theory, and information diffusion theories and research. The majority of ACE members also rated communication skill development as more important than management or research skill development when choosing a primary focus of the degree. Members agreed that the degree should include a broad spectrum of communication subject areas and a broad agricultural base to augment the communication emphasis. A majority of members indicated that internships should be required only for students with no prior work experience in communication. Members also indicated that communication skill courses and technical agriculture courses should be part of the degree program and not considered conditional requirements.

Based on the findings of the study, the researchers concluded that a Master of Science degree in Agricultural Communication should include a theoretical base and provide practical experience. The master's degree should also be flexible and offer a variety of courses. Requirements cannot be too rigid because students enter the degree program with varied educational and work experience backgrounds. The degree also needs to be flexible to incorporate the number of content areas ACE members indicated should be part of the degree curriculum.

The findings indicate that content area selection is associated with the percentage of time devoted to administrative duties, production activities, formal classroom teaching, and research activities; for example, production personnel have a different content focus when compared with administrators or teachers. Therefore, when selecting specific content areas to be included in a Master of Science degree in Agricultural Communication, the researchers recommend that a variety of agricultural communication professionals be consulted. Involving a variety of professionals in the planning process will help to ensure a more balanced graduate degree program.

The researchers suggest that a multi-track degree be developed to incorporate varying levels of experience and knowledge. Providing options will ensure that advanced students are not penalized, and beginning students can strengthen weak areas.

The researchers also suggest that more agricultural communication courses be developed. According to Reisner (1990), agricultural units at the bachelor's level offer an average of four to five communication courses per institution. The remaining com- 
munication coprseworkis lesatedin otherdepartments (i.e. Communication, Journalism). While developing additional agricultural communication course work is suggested, these courses should not duplicate existing courses. Efforts should be made to promote coordination to avoid overlapping course content.

\section{Recommendations}

The following recommendations are based on the research findings. These recommendations are appropriate for further study.

1. Similar studies should be conducted with other communication organizations and professionals to obtain a broader perspective of the perceptions of a Master of Science degree in Agricultural Communication. These other professionals are represented in, but not limited to, the following professional agricultural communication organizations: American Agricultural Editors' Association, Agricultural Relations Council, Cooperative Communicators Association, Livestock Publications Council, National Association of Farm Broadcasters, National Association of Agricultural Journalists, and National Agri-Marketing Association. Curriculum planners and employers can use the comparative data from these studies to develop graduate level programs in agricultural communication.

2. A study should be conducted to determine the appropriate college to house the Department of Agricultural Communication. The College of Agriculture does not necessarily have to house the department. Perhaps the needs of agricultural communication students can be better met by houssing the the, Alepartment of Agricultural Communication in another college such as Communication or Journalism. Determining the primary function of a Master of Science degree in Agricultural Communication will help decide which college should house the Department of Agricultural Communication.

3. A study should be conducted to investigate the role of the Department of Agricultural Communication. Perhaps the department could perform a coordinating function with other departments in the university. Interdisciplinary programs should be considered to draw upon the strengths of several academic departments.

4. Establishing departments of Agricultural Communication will create a need for qualified faculty with expertise in agricultural communication. A study should be conducted to determine if a doctoral degree in Agricultural Communication is needed to prepare qualified faculty for university positions. Investigating the difference in course content between a Master of Science degree and a Doctor of Philosophy degree is essential. Determining the unique contribution of a doctoral program in agricultural communication is needed to avoid duplicating the master's degree program.

5. The current study defined the content area for a Master of Science degree in Agricultural Communication in very general terms (i.e., writing, graphics, leadership development). Additional studies should focus on each of the content areas in more detail. For example, the content area of writ- 
ing could include the following subcategories to assist in clarifying the term: technical writing, science writing, creative writing, feature writing, and newswriting.

6. Research studies should be conducted that focus on additional content areas to be included in a Master of Science degree in Agricultural Communication such as: satellite teleconferencing, ethics in communication and agriculture, cross-cultural communication, international perspectives, and problem solving/critical thinking.

\section{References}

Dillman, D. A. (1978). Mail and telephone surveys: The total design method. New York: John Wiley and Sons.

Duncan, C. (1957). An evaluation of the agricultural journalism curriculum in land grant colleges. Unpublished master's thesis, University of Missouri, Columbia.

Evans, J. (1972). Broadening the academic base in agricultural communication. ACE Quarterly, 55(4), 30-40.
Evans, J. (1985). International communications education and training: A look to the future. ACE Quarterly, 68(2), 1-15.

Evans, J. and Bolick, J. (1982). Today's curricula in agricultural communications. ACE Quarterly. 65(1), 29-38.

Krejcie, R. V. and Morgan, D. W. (1970). Determining sample size for research Activities. Educational and Psychological Measurement, 30, p. 607-610.

Kroupa, E. and Evans, J. (1973). New directions in agricultural communications curricula. ACE Quarterly, 56(3), 228-38.

Kroupa, E. and Evans, J. (1976). Characteristics and course recommendations of agricultural communicators: An update. ACE Quarterly, 59(1), 23-31.

Mitchell, William G. (1956). Professional qualifications for a career in agricultural journalism and communications. Master's thesis, University of Florida.

Reisner, A. (1990a). An overview of agricultural communications programs and curricula. Journal of Applied Communications, 74(1), 817.

Reisner, A. (1990b). Course work offered in agricultural communications programs. Journal of Applied Communications, 74(1), 18-25. 